Bangladesh J. Plant Taxon. 27(2): 439-446, 2020 (December)

(C) 2020 Bangladesh Association of Plant Taxonomists

\title{
USEFUL VALUABLE PLANTS OF MAITHILI COMMUNITY IN EASTERN NEPAL: AN ETHNOBOTANICAL STUDY
}

\author{
Anand Raj Mallik*, Sujan Chaudhary ${ }^{1}$ and Sabitri Shrestha \\ Department of Biology, Central Campus of Technology, \\ Tribhuvan University, Dharan, Nepal
}

Keywords: Ethnobotany; Maithili community; Eastern Nepal.

Ethnobotany is considered to include all studies, which focus on the mutual relationship between plants and traditional people (Cotton and Wilkie 1996; Harshberger, 1896). Nepal is the multi-ethnic, multi-lingual and multi-religious nation with diversified culture and tradition. There are more than 123 caste/ethnic groups speaking 123 languages (CBS, 2011). The ethnic communities have significant customary knowledge on utilization of plant and plant parts and there is a long tradition of transferring this indigenous knowledge from generation to generation (Acharya and Acharya, 2009). However, all the ethnic groups have their own tradition, culture and way of living (Chaudhary et al., 2020). Various communities in Nepal are still giving continuation to the use of plants for their living. Till date, several ethnobotanical studies have been carried out in Nepal to uncover the uses of plants in several communities and rural places (Rajbhandari, 2001; Joshi and Joshi, 2008; Acharya and Acharya, 2009; Malla and Chhetri, 2009; Thapa, 2012; Malla et al., 2015; Chaudhary et al., 2020). Maithili community is one of the ethnic groups with the population of 3.1 million which is about $11.67 \%$ of the total population of Nepal (CBS, 2011). Maithili people have developed the diversified use of plants for food, medicine, religious and cultural activities and other purpose.

Although, many ethnobotanical studies have been conducted in different parts of the country, ethnobotanical studies of Maithili community have not been documented yet in Nepal. However, Jha and Jha (1996) have documented ritualistic significance of plants associated with Maithili traditions in Northern Bihar, India. Thus, the present study was conducted to identify and record the uses of medicinal and other plant of Maithili people in the Ramdhuni municipality, Sunsari district, Nepal. This study has recorded the use of plants in various purposes, nevertheless, the doses and way of plant intake for medicinal use was not mentioned.

Ramdhuni municipality is situated in the Sunsari district, Eastern Nepal (Fig. 1). It lies at $87^{\circ} 10^{\prime} \mathrm{E}$ and $26^{\circ} 42^{\prime} \mathrm{N}$, where altitude ranges up to $185 \mathrm{~m}$ above sea level and occupies total area of $91.7 \mathrm{~km}^{2}$ and total population 52,328 . The average annual rainfall is $1100 \mathrm{~mm}$. The study was conducted in 3 villages of ward number 1 in Ramdhuni municipality. Before the collection of data, the participants were made sure about proper use of the data. PRA method was applied for the collection of data. Total 14 peoples ( 9 females and 5 males) from 2 villages were involved in the study for the collection of data. All the people involved in PRA were over 50 years of age. After surveying the area, group discussion was performed with the group of local Pujaris, old peoples and farmers to explore local illness and curing beliefs and plants used for medicine, edible purpose and other uses. Plant species were collected from the study area and herbarium sheets of each species were prepared (Lawrence, 1951). The specimens were carefully studied, identified with

*Corresponding author, E-mail: mallikraj.anand@gmail.com.

${ }^{1}$ Department of Botany, Amrit Science Campus, Kathmandu, Tribhuvan University, Nepal. 
the help of experts, and voucher specimens. Further confirmation was made by using available literatures (Hooker, 1872-1897; Hara et al., 1978; Siwakoti and Verma, 1996). Well identified herbarium specimens were preserved in herbarium of Central Campus of Technology, Dharan.

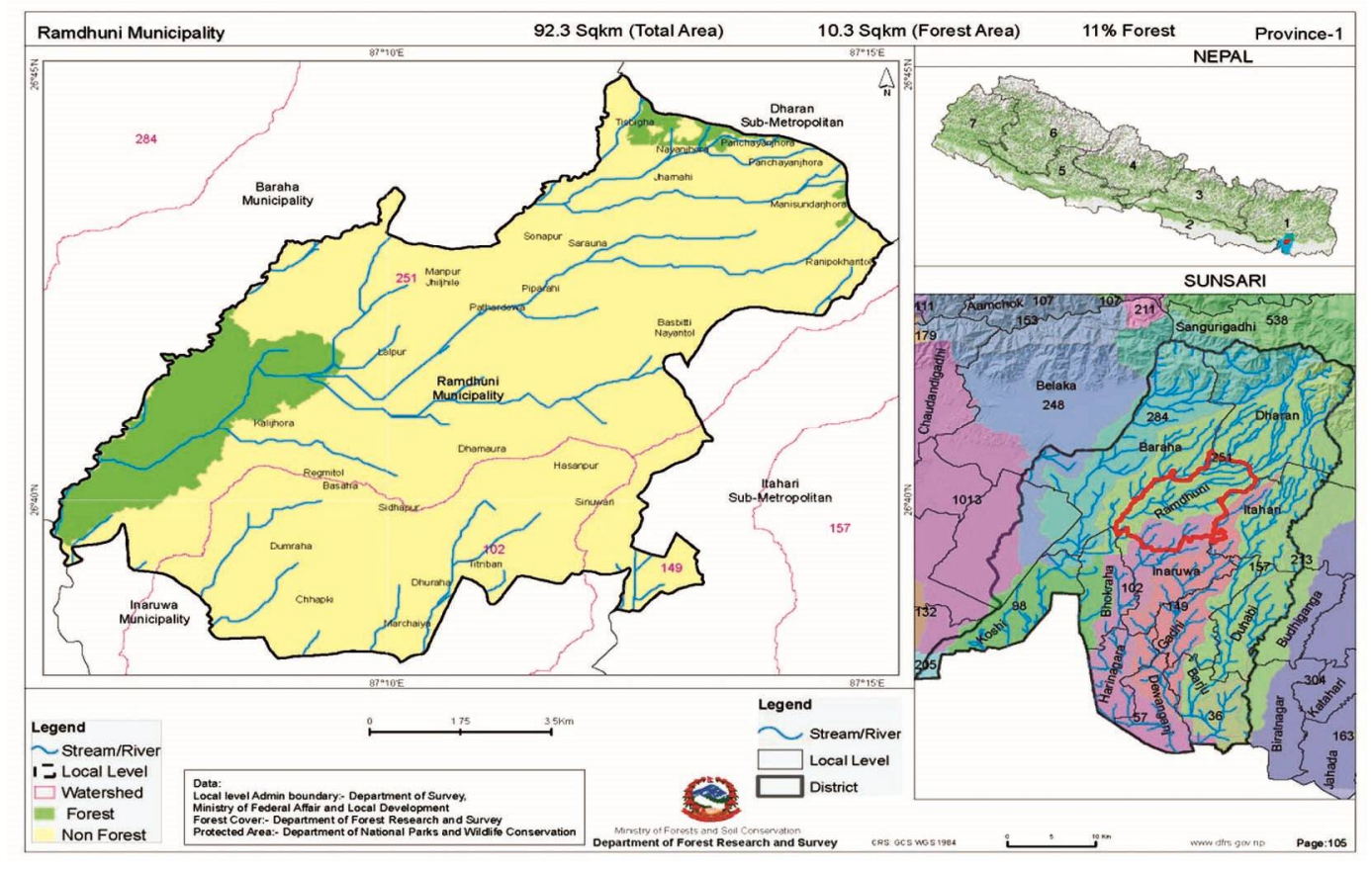

Fig. 1. Map of the study area showing Nepal, Sunsari district and Ramdhuni municipality in top right, bottom right and left side of the map respectively.

The present study reveals 37 plant species used by Maithili community of Ramdhuni municipality of Sunsari district, Nepal. These plants were enlisted with their life forms, scientific names, uses and other informative details (Table 1). Among 37 plant species, 29 were found to be dicotyledons and 8 were reported as monocotyledons. The common life form among the listed plants was herb (40.5\%). However, other life forms have also been reported followed by trees (24.3\%) and shrubs (18.9\%). Herbs are often found to be the most used plant types due to their abundance (Shrestha and Dhillion, 2003; Uprety et al., 2010). Uprety et al., (2011) and Siwakoti (2006) have also reported the dominance of herbs in their study. Maithili community vigorously extracted the leaves for their daily survival followed by whole plants and roots/rhizomes (Fig. 2). This might be due to the easy availability of leaves than other plant parts. Acharya and Acharya (2009) and Singh (2017) have also reported similar results in their studies showing vigorous use of leaf than other plant parts. The present study reported most of the plants are used as medicine or food, as previously observed in other areas of Nepal (Shrestha et al., 2003; Uprety et al., 2008).

Herbs are often found to be the most used plant types for medicinal purpose because of their abundance (Shrestha and Dhillion, 2003; Uprety et al. 2010). Total 20 species of present study were known for the medicinal use followed by religious and food purpose (Fig. 3). Category listed as "Others" include the plant used for dye and sedative purpose (Fig. 3). Among the 20 medicinal 


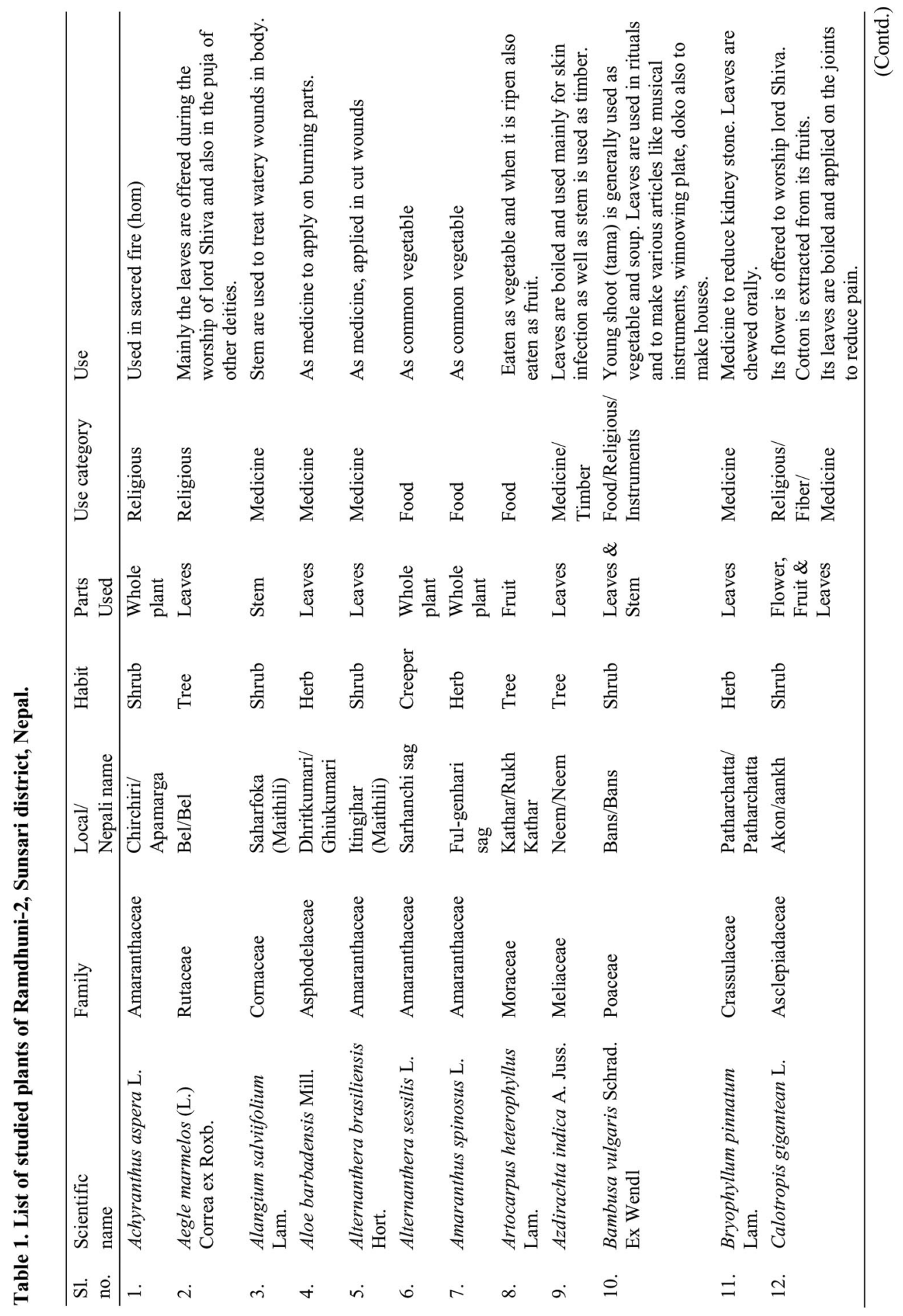




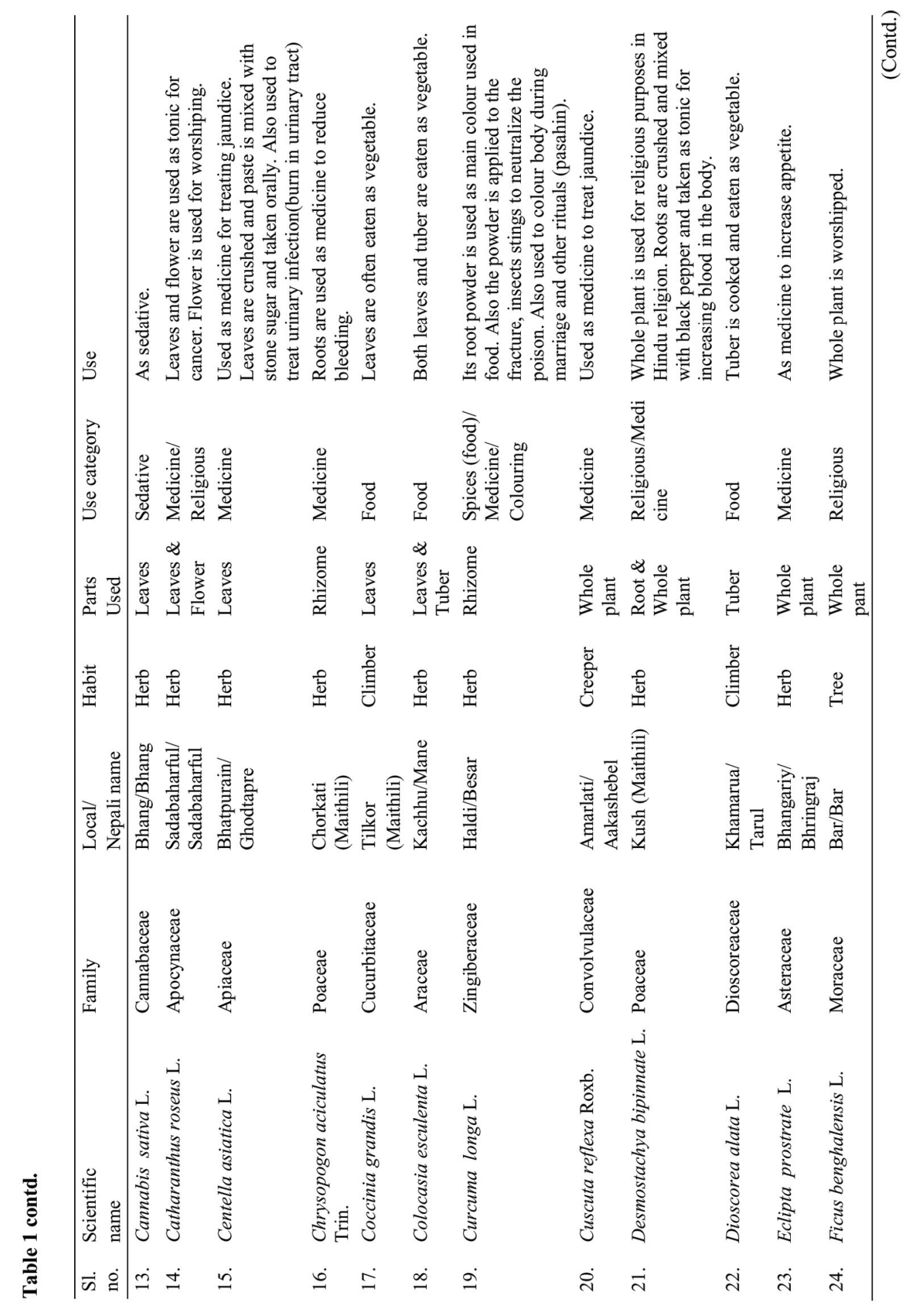




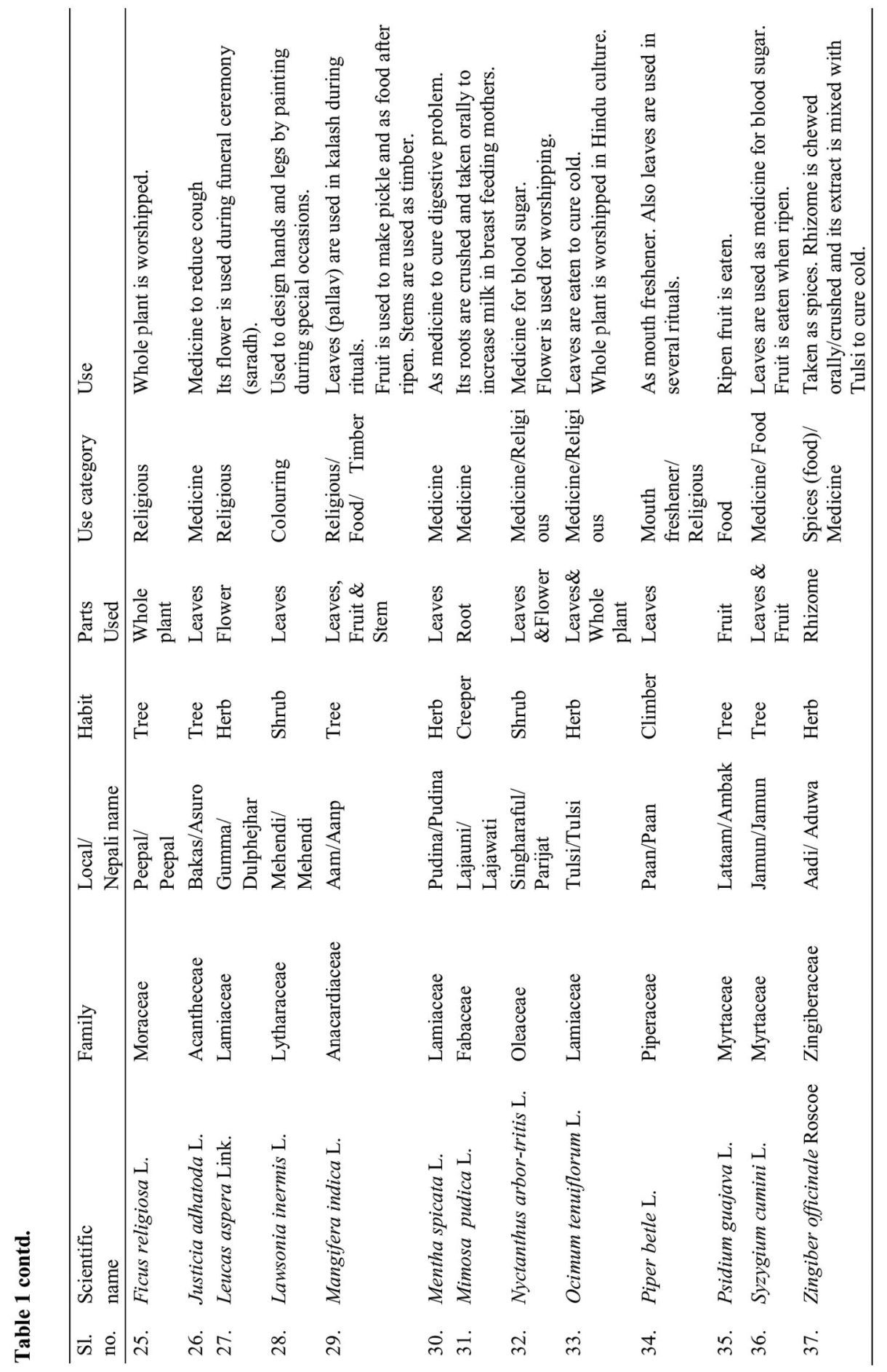




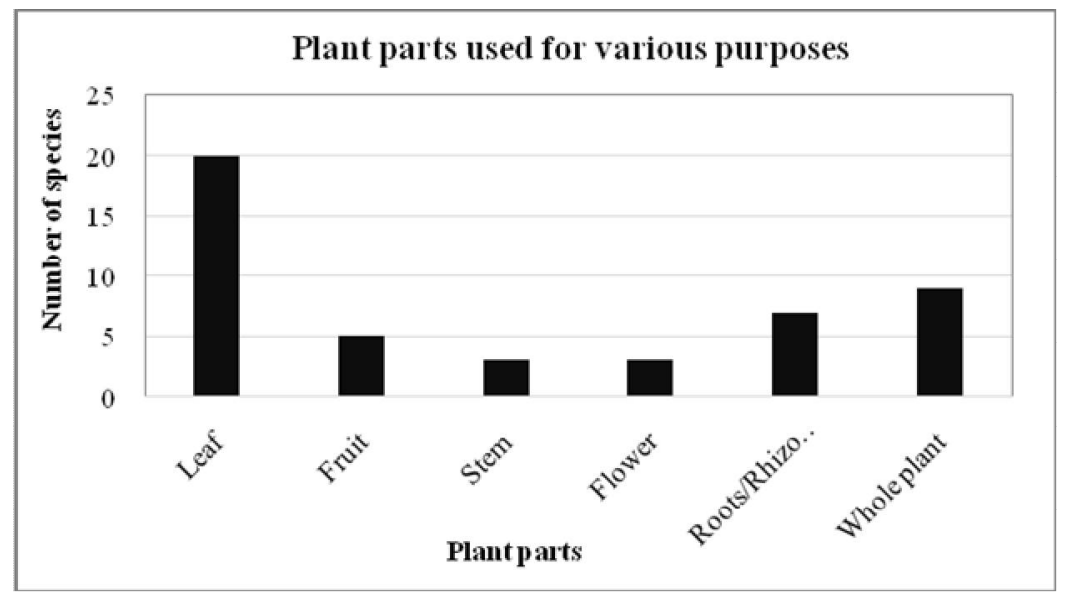

Fig. 2. Parts of plant species of the study area used for various purposes.

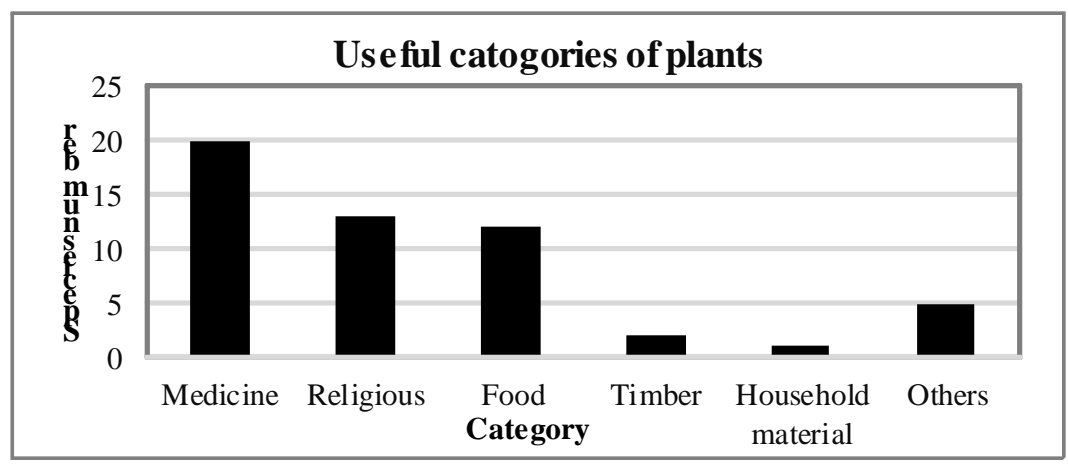

Fig. 3. Useful categories of plant species of the study area.

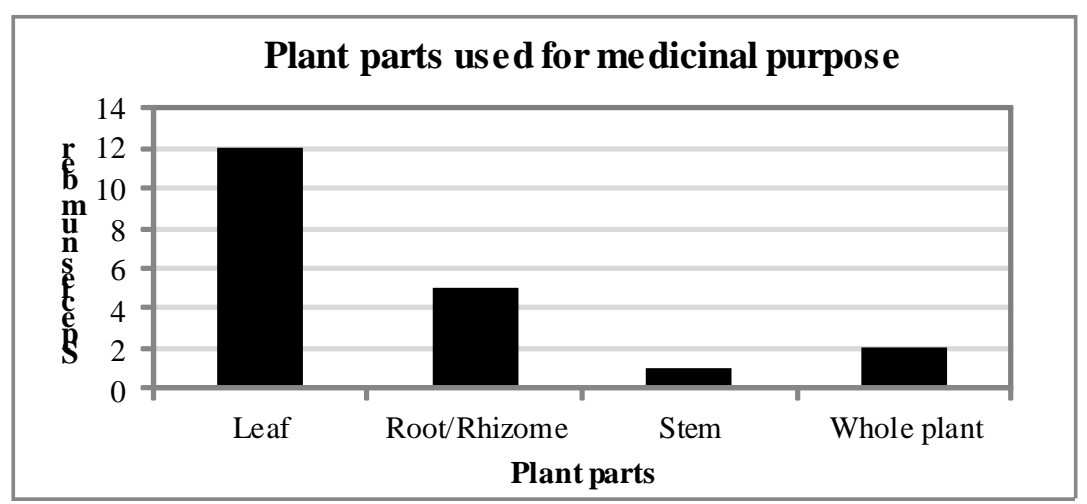

Fig. 4. Parts of plant species of the study area used for medicinal purpose. 
species, 12 species were recognized where leaves were used for medicinal purpose followed by root (Fig. 4). The medicinal use of Justicia adhatoda, Amaranthus spinosus, Calotropus gigantean, Aegle marmelos, Azadirachta indica, Centella asiatica and Cuscuta reflexa were previously reported for various medicinal purposes like fever, for hastening suppuration, jaundice and stomach pain (Acharya and Acharya 2009; Dangol and Gurung 1991; Chaudhary et al., 2020). Joshi and Joshi (2001) have mentioned the use of Mentha spicata for diarrhoea and stomach ache. Baral and Kurmi (2006) has reported the use of Cuscuta reflexa for the cure of jaundice. Similarly, Manandhar (2002) has described the use of Zingiber officinale for the treatment of sore, wound, cough and cold. Moreover, the food diversity in wild species allowed for variety in family diet and contributes to household food security (Balemie and Kebebew, 2006). Among the 37 plant species, 25 were recorded to have single use category and eight species were reported to have two use values and followed by four species with three use value. Malla and Chhetri (2009), Uprety et al., (2011) and Chaudhary et al., (2020) recorded several plant species with more than one use value. Although, the previous studies have shown that the multiple use value of plants dominated over one use value, the use of plants in Maithili community in fodder is almost negligible because animal husbandry is not popular within Maithili community in this region. However, the results of our study resembled with that of the study by Chaudhary et al. (2020) conducted on similar altitude, area and geography.

The old local people and Pujaris of the Maithili community have a sound knowledge of the medicinal and other use value of the different plants. However, young aged people were not found to be interested in traditional medicine practices. The plants of this study were found to be important source for the health care and social life of tribal people. Although only 37 species were identified during this study, it is believed that there may be other species of plants used as medicines by this Maithili community. Therefore, further inventories in Maithili community of Nepal should be conducted to explore more ethnobotanical knowledge that this community has achieved since long period of time. Moreover, phytochemical and pharmacological analysis should be performed to ensure the effectiveness of studied medicinal plants.

\section{Acknowledgements}

We want to thank local villagers for exchanging valuable information regarding studied plant species.

\section{References}

Acharya, R. and Acharya, K.P. 2009.Ethnobotanical study of medicinal plants used by Tharu community of Parroha VDC, Rupandehi district, Nepal. Scientific world. 7(7): 80-84. https://doi.org/10.3126/ sw.v7i7.3832.

Balemie. K. and Kebebew, F. 2006. Ethnobotanical study of wild edible plants in Derashe and Kucha Districts, South Ethiopia. Journal of Ethnobiology and Ethnomedicine. 2(1): 53. https://doi.org/10.1186/ 1746-4269-2-53.

Baral, S.R. and Kurmi, P.P. 2006. Compendium of medicinal plants in Nepal. Rachana Sharma.

Central Bureau of Statistics. National Population and Housing Census 2011. Kathmandu: Central Bureau of Statistics. 2011. National Planning Commission, Vol. I, pp. 4.

Chaudhary, S., Magar, G.T., Sah, S.N. and Parajuli, S. 2020. Ethnic Plants of Tharu Community of Eastern Nepal. International Journal of Applied Science and Biotechnology. 8(2): 223-230. https://doi.org/ 10.3126/ijasbt.v8i2.28325

Cotton, C.M., and Wilkie, P. 1996. Ethnobotany: principles and applications (No. Sirsi) i9780471955375). Chichester: John Wiley \& Sons Ltd. Baffins Lane, Chichester, West Sussex, England. 
Dangol, D.R. and Gurung, S.B. 1991. Ethnobotany of the Tharu tribe of Chitwan district, Nepal. International Journal of Pharmacognosy. 29(3): 203-209.https://doi.org/10.3109/13880209109082879

Hara, H., Stearn, W.T. and Williams. L.H.J. 1978. An enumeration of the flowering plants of Nepal; 1978, a joint project of the British Museum (Natural History) and the Univ. of Tokyo-v. 1:(Gymnospermae and Angiospermae (Monocotyledones). London (UK) BM(NH)

Harshberger, J.W. 1896. The purposes of ethno-botany. Botanical gazette.21(3): 146-154.

Hooker, J.D.1872-1897. Flora British India, 1. L, Reeve, London.

Jha, V. and Jha, J.S.1996. Ritualistic significance of plants associated with Maithili traditions in North Bihar. Rays and Ways of Indian Culture. 193.

Joshi, K.K. and Joshi, S. D. 2001. Genetic heritage of medicinal and aromatic plants of Nepal Himalayas. Buddha Academic Publishers and Distributers. $1^{\text {st }}$ Eds. Putali Sadak, Kathmandu, Nepal.

Joshi, K. and Joshi, A. 2008. Swertia L. (Gentianaceae) in Nepal Himalaya: Checklist, phytogeography, ethnobotany and conservation status. Ethnobotanical Leaflets. 1: 43.

Lawrence, G.H.M. 1951. Taxonomy of vascular plants. New York: Macmillan. United States, America.

Malla, B. and Chhetri, R.B. 2009. Indigenous knowledge on ethnobotanical plants of Kavrepalanchowk district. Kathmandu University Journal of Science, Engineering and Technology. 5(2): 96-109.

Malla, B., Gauchan, D.P. and Chhetri, R.B. 2015. An ethnobotanical study of medicinal plants used by ethnic people in Parbat district of western Nepal. Journal of Ethnopharmacology. 165: 103-117.https:// doi.org/10.1016/j.jep.2014.12.057.

Manandhar, N. P. 2002. Plants and people of Nepal. Timber press. Portland, America.

Rajbhandari, K. R. 2001. Ethnobotany of Nepal. Ethnobotanical society of Nepal. Nepal.

Shrestha, K. K., Tiwari, N. N., Rajbhandari. S., Shrestha, S., Uprety, Y. and Poudel, R.C. 2003. Non timber Forest Products (NTFPs) in the critical bottlenecks and corridors of Terai Arc- Landscape Nepal: Documentation, utilization, trade and people's livelihood. Kathmandu, Nepal. WWF Nepal Programme.

Shrestha, P.M. and Dhillion, S.S. 2003. Medicinal plant diversity and use in the highlands of Dolakha district, Nepal. Journal of ethnopharmacology. 86(1): 81-96. https://doi.org/10.1016/S0378-8741(03)00051-5.

Singh, S. 2017. Ethnobotanical study of wild plants of Parsa district, Nepal. Ecoprint: An International Journal of Ecology. 24:1-12. https://doi.org/10.3126/eco. v24i0.20641.

Siwakoti, M. 2006. An overview of floral diversity in wetlands of Terai region of Nepal. Our Nature. 4(1): 83-90. https://doi.org/10.3126/on.v4i1.506.

Siwakoti, M. and Varma, S.K. 1996.Medicinal plant of the Terai of east Nepal. Jnl eco. Taxon Additional series- 1996. 12: 423-438.

Thapa, S. 2012. Medico-ethnobotany of Magar community in Salija VDC of Parbat district, central Nepal. Our Nature. 10(1): 176-190. https://doi.org/10.3126/on. v10i1.7780.

Uprety, Y., Boon E.K. and Poudel, R.C. 2008. Traditional use of Plant Resources by Bankariya ethnic group in Makwanpur district, Central Nepal. Germany: Grin Publisher.

Uprety, Y., Asselin, H., Boon, E.K., Yadav, S. and Shrestha, K.K. 2010. Indigenous use and bio-efficacy of medicinal plants in the Rasuwa District, Central Nepal. Journal of ethnobiology and ethnomedicine. 6(1): 3. https://doi.org/10.1186/1746-4269-6-3

Uprety, Y., Poudel, R.C., Asselin, H. and Boon, E. 2011. Plant biodiversity and ethnobotany inside the projected impact area of the Upper Seti Hydropower Project, Western Nepal. Environment, Development and Sustainability. 13(3): 463-492.https://doi.org/10.1007/s10668-010-9271-7 